\title{
COLOUR VISION OF THE FORAGING SWALLOWTAIL BUTTERFLY PAPILIO
} XUTHUS

\author{
MICHIYO KINOSHITA ${ }^{1}$, NAOKO SHIMADA ${ }^{1}$ AND KENTARO ARIKAWA ${ }^{1,2, *}$ \\ ${ }^{1}$ Graduate School of Integrated Science, Yokohama City University, Yokohama and ${ }^{2}$ PRESTO, Japan Science and \\ Technology Corporation, Japan \\ *Author for correspondence at address 1 (e-mail: arikawa@yokohama-cu.ac.jp)
}

Accepted 28 October; published on WWW 14 December 1998

\begin{abstract}
Summary
This paper demonstrates that foraging summer-form females of the Japanese yellow swallowtail butterfly Papilio xuthus have colour vision. The butterflies were trained to feed on sucrose solution placed on a disk of a particular colour in a cage set in the laboratory. After a few such training runs, a butterfly was presented with the training

training colour was also correctly selected when it was covered with neutral density filters to reduce its brightness, or even when the colour was presented together with disks of a variety of shades of grey. These results demonstrate convincingly, for the first time, that a butterfly has true colour vision.
\end{abstract} colour randomly positioned within an array of disks of other colours, but with no sucrose solution. The results indicate that the butterflies learn rapidly to select the training colour reliably among different colours. The
Key words: vision, colour, butterfly, learning, spectral receptor, retina, behaviour, Papilio xuthus.

\section{Introduction}

By observing colourful butterflies feeding on colourful flowers, it is easy to believe that these animals might have colour vision. However, a number of attempts in the past several decades to demonstrate colour vision in butterflies have not been fully successful in scientific terms (Silberglied, 1984).

Colour vision is the ability to discriminate visual stimuli solely on the basis of their chromatic content irrespective of their brightness (Goldsmith, 1990). The demonstration of colour vision in animals is not a simple issue. The existence of multiple types of spectral receptor in the retina is certainly a requirement for colour vision, but this is of course not sufficient. Colour vision must be demonstrated by behavioural tests in which animals can be trained to discriminate a particular colour (or visual spectral stimulus) from other colours (spectra) or achromatic stimuli.

There are a number of reports describing the relationship between coloured stimuli and certain behaviour patterns of butterflies. Pioneering work by Ilse and Vaidya (1955) showed that foraging Papilio demoleus (Papilionidae) spontaneously visited artificial flowers coloured blue and purple. Pieris napi (Pieridae) was shown to feed on artificial flowers of certain colours; the preferred colour varied among individuals. The preference changed if the flowers of the preferred colour no longer contained nectar (Goulson and Cory, 1993). Aglais urticae (Nymphalidae), Pararge aegeria (Satyridae) and Pieris brassicae (Pieridae) were shown to prefer one particular colour irrespective of the brightness when searching for food (Scherer and Kolb, 1987a,b). In Pieris brassicae, different behavioural responses are elicited by different spectral ranges of light: escape is elicited by $320-420 \mathrm{~nm}$, feeding by $420-500 \mathrm{~nm}$ and $590-610 \mathrm{~nm}$, and oviposition by $520-580 \mathrm{~nm}$ or $590 \mathrm{~nm}$ (Scherer and Kolb, 1987a). These are so-called wavelength-specific or hard-wired behaviours, in which colour vision is not necessarily involved (Goldsmith, 1990; Menzel, 1985). More recently, Battus philenor (Papilionidae) (Weiss, 1997) and Pieris rapae (Pieridae) (Kandori and Ohsaki, 1998) appeared to be attracted by artificial flowers of certain colours. Thus, many butterflies seem to use colour signals for conducting a variety of behaviours, although there is still no conclusive evidence that butterflies discriminate between coloured objects solely on the basis of their chromatic content irrespective of brightness.

We have established an indoor experimental system in which we trained butterflies to visit a coloured disk associated with food in order to investigate their colour vision. Our results show that the Japanese yellow swallowtail butterfly Papilio xuthus can be trained to feed on coloured disks in a simple apparatus. By using this apparatus, we have demonstrated that foraging Papilio xuthus can use colour when they search for food in nature.

\section{Materials and methods}

\section{Animals}

We used summer-form virgin females of the Japanese yellow swallowtail butterfly Papilio xuthus $\mathrm{L}$. The butterflies 


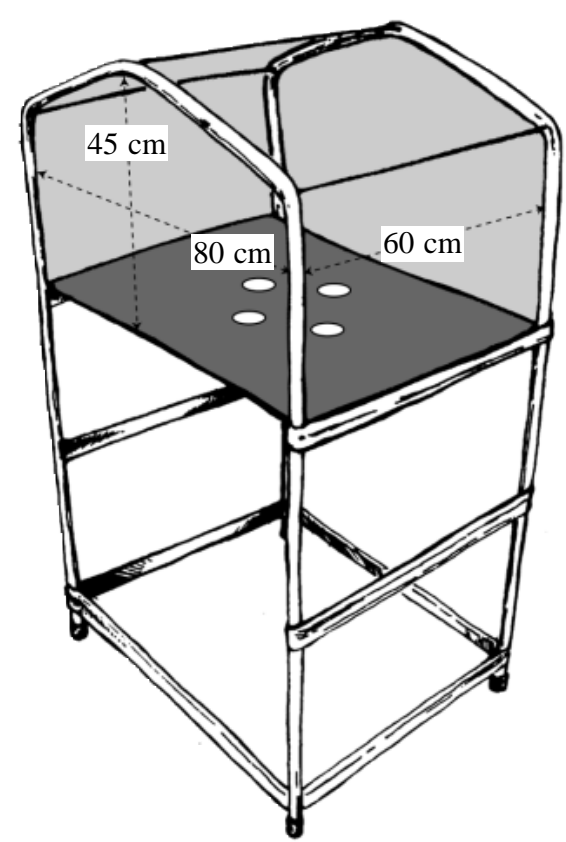

Fig. 1. The cage used for the behavioural experiments.

were supplied from a laboratory culture derived from eggs laid by females caught in the field in Yokohama, Japan. The hatched larvae were fed on fresh citrus leaves at $25^{\circ} \mathrm{C}$ under a $16 \mathrm{~h}: 8 \mathrm{~h}$ light:dark regime. Pupae were allowed to emerge at $28^{\circ} \mathrm{C}$ in a plastic box covered with gauze under a $12 \mathrm{~h}: 12 \mathrm{~h}$ light:dark regime. The day of emergence was defined as postemergence day 1 for that individual.

\section{Behavioural experiments}

All experiments were performed in an indoor cage constructed from steel piping covered with nylon net
$(80 \mathrm{~cm} \times 60 \mathrm{~cm} \times 45 \mathrm{~cm})$. The floor of the cage was made of wood and was covered with black cardboard (Fig. 1). The cage was illuminated by eight halogen lamps $(300 \mathrm{~W})$ and six fluorescent tubes $(40 \mathrm{~W})$. The intensity of illumination was approximately $6000 \mathrm{~lx}$ at the floor of the cage. The room temperature was set at $28^{\circ} \mathrm{C}$.

\section{Stimuli}

Stimuli were presented by placing disks of coloured paper (Nihon Shikisai Training colour 200, 1995 version) on the black floor. For efficient presentation of the stimuli, we prepared four patterns (Fig. 2), each consisting of a certain number of disks (diameter $5-10 \mathrm{~cm}$ ) of a particular colour arranged on a sheet of black cardboard $(55 \mathrm{~cm} \times 35 \mathrm{~cm})$. The diameters of the disks in any one pattern were always identical. For patterns containing disks of more than one colour, we prepared three sheets with different arrays of the same set of colours for each pattern (Fig. 2A-D), which were used to randomize the relative positions of different colours. The patterns were covered with anti-reflection glass when presented.

Fig. 3 shows the reflectance spectra in the wavelength region between 300 and $700 \mathrm{~nm}$, measured using a spectrometer (S2000, Ocean Optics, Inc., USA), of all the coloured papers used in the present experiments (Fig. 3A-C). The irradiance spectrum of the illumination was measured as the spectrum of the light reflected from the magnesium-oxide-coated surface (Fig. 3D). The sharp spikes in Fig. 3D are produced by the fluorescent lamps used to illuminate the arena.

\section{Training and tests}

We examined the foraging behaviour of butterflies in a laboratory cage. We defined a 'visit' as a positive response when a butterfly landed and extended its proboscis towards a coloured disk. In all the following training sessions and tests,
Fig. 2. Patterns presented on the floor of the cage. Each pattern has 1-13 coloured disks on black cardboard. (A) Training pattern. (B) Four-colour pattern. Disks of red, yellow, green and blue were presented. (C) Thirteen-colour pattern. In addition to the four colours used in B, seven other colours (see Fig. 3B) and two shades of grey (GR1 and GR2, see Fig. 3C) were presented. (D) Grey-scale pattern. A disk of one of the four colours used in B was presented with seven different shades of grey (GR1-GR7, see Fig. 3C).
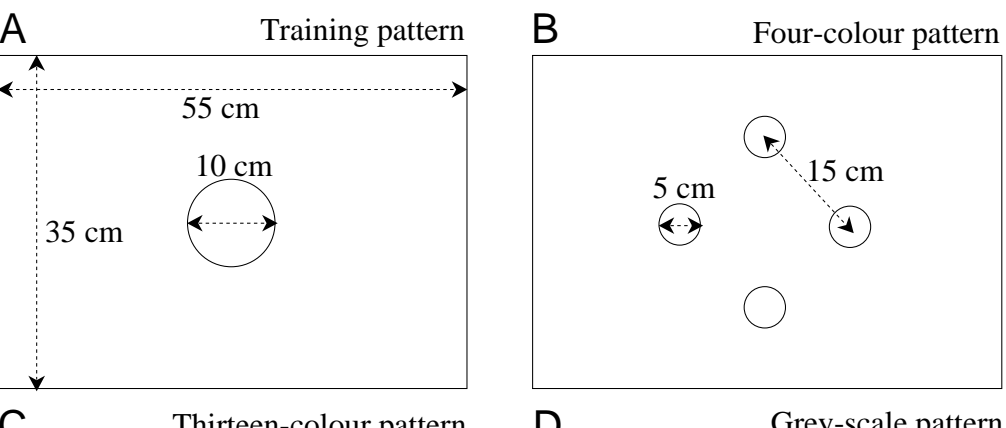

C Thirteen-colour pattern
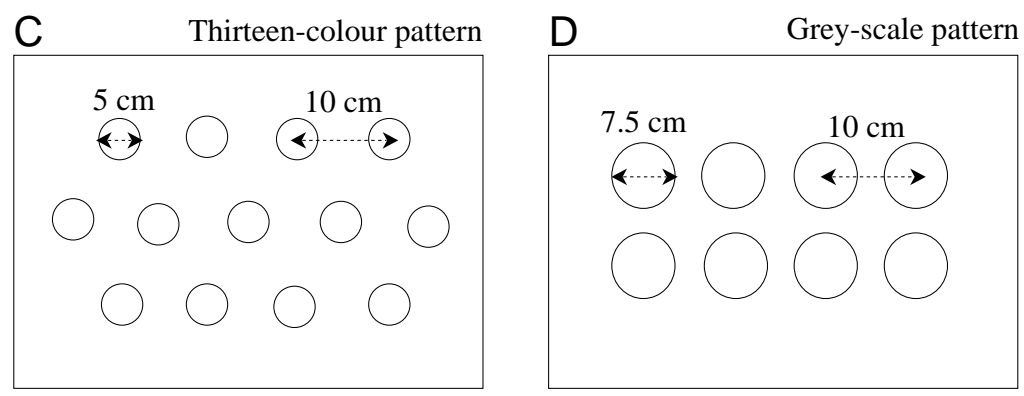
we released only one butterfly in the cage at one time. Also, we carefully removed possible odour and visual cues left by previous animals in the arena by wiping the anti-reflection glass
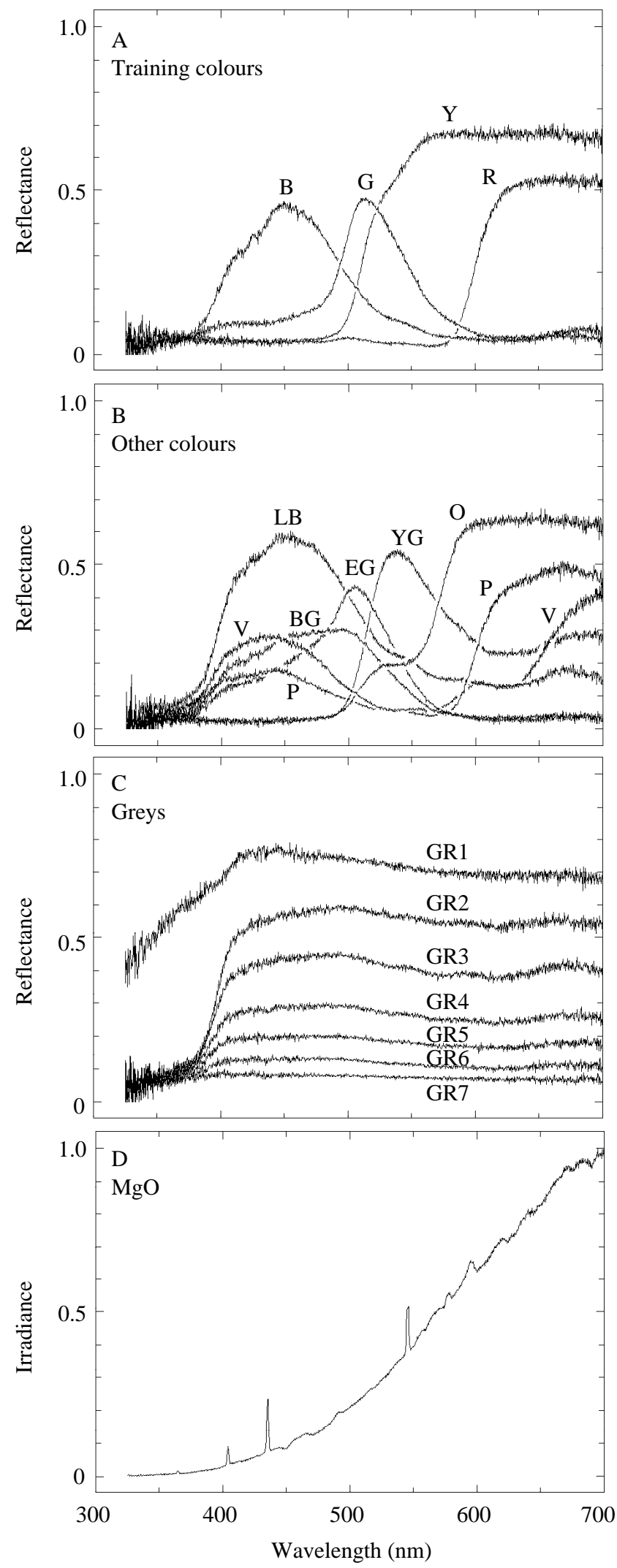

with wet cloths as frequently as possible. When presenting patterns with multiple disks, we changed the relative positions of the disks randomly to avoid any effect of disk position, either positive or negative, on foraging behaviour.

When the butterfly visited any disk for a criterion number of times (1, 5 or 10 times depending on the experiments; see below), we removed the individual from the cage and released another. Most butterflies finished the task within $1 \mathrm{~min}$. We rejected butterflies that did not finish the task within $5 \mathrm{~min}$. Approximately $10 \%$ of the butterflies tested were rejected by this criterion.

\section{Innate colour preference}

Newly emerged inexperienced butterflies were kept in a plastic box without food for 3 days. On post-emergence day 4 , the naive, starved butterflies were released in the cage, one by one, with a four-colour pattern (Fig. 2B) without sucrose solution presented on the floor. To eliminate any possible effect of the position of the disks, either positive or negative, we changed the relative position of the four disks for each individual. The colour chosen at the first visit of each individual was assumed to reflect its innate preference.

\section{Colour learning}

Newly emerged butterflies were kept in a plastic box without food for 1 day. On post-emergence day 2, butterflies were individually trained by letting them drink $100 \mu \mathrm{l}$ of $5 \%$ sucrose solution on the colour disk of a training pattern (Fig. 2A). Training with the same pattern was repeated once a day for 9 days until post-emergence day 10. Butterflies were manually placed on the disk until they learned to feed on the disk spontaneously, usually within 2 days.

To evaluate the effect of each training session, we performed the following test every day before carrying out the training session. At the beginning of the test, $5 \mu \mathrm{l}$ of $5 \%$ sucrose solution was offered on the disk of the training pattern in order to avoid the effect of 'negative' training caused by the butterfly visiting the trained colour without receiving any reward. Immediately after the butterfly had taken off from the pattern, usually after consuming the sucrose solution, the training pattern was removed and the four-colour pattern was presented (Fig. 2B). We let the butterfly visit the disks five times and counted the number of visits to each colour. The array of colours on the pattern was changed after the butterfly had visited the third disk in order to avoid the effect of the butterfly learning the disk positions.

Fig. 3. Reflectance spectra of the coloured papers used in these experiments. (A) Colours used in the four-colour pattern. (B) Colours used in the 13-colour pattern together with the four colours in A and two shades of grey in C. (C) Seven different shades of grey. (D) Irradiance spectrum of the illumination measured as the spectrum of the light reflected from the $\mathrm{MgO}$-coated surface. $\mathrm{B}$, blue; BG, blue-green; EG, emerald-green; G, green; GR, grey; LB, light blue; O, orange, P, purple; R, red; V, violet; Y, yellow; YG, yellowgreen. 
On post-emergence day 11 , the butterflies were tested on the 13-colour pattern before the training session (Fig. 2C). We let the butterflies visit the disks 10 times, and counted the number of visits to each colour. We removed the butterfly from the cage immediately after it had visited disks 10 times. The array of colours was changed twice, after the butterfly had visited the third and the sixth disks.

\section{Selection from grey scale}

On post-emergence day 11 , butterflies trained to a certain colour were tested on a pattern with a disk of the trained colour and seven disks of different shades of grey (Fig. 2D). We let them visit the disks five times, and counted the number of visits to each disk. The position of the coloured disk was changed after the third visit.

\section{Selection of the trained colour of reduced brightness}

Butterflies trained to a certain colour for 9 days were tested on the four-colour pattern (Fig. 2B). The brightness of the trained colour was reduced by placing a neutral density gelatin filter (ND) $(5 \mathrm{~cm} \times 5 \mathrm{~cm})(\mathrm{ND} 1, T=80 \%$; ND2, $T=63 \%$; ND3, $T=50 \%$; ND4, $T=40 \%$; ND5, $T=30 \%$, where $T$ is transmittance; Kodak Wratten Neutral Density Filter no. 96) over the disk. The other disks were covered with transparent

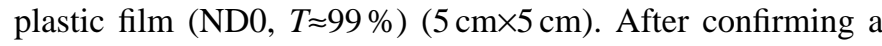
visit of the butterfly to the trained disk of the original brightness, an ND1 filter was placed over the disk. Subsequently, the brightness was reduced in stepwise manner. When the butterflies visited a wrong colour once, or did not visit any colour for $5 \mathrm{~min}$, they were considered to be unable to discriminate the training colour from the other colours. The neutral density filter was then removed to confirm that the butterflies still retained the motivation to forage by observing their visits to the colour of original brightness.

\section{Results \\ Colour preference of naive butterflies}

Under the conditions used in our experiments, the butterflies visited disks of a certain colour on which to feed: they landed close to or on the disk with the proboscis fully extended and searched for nectar by probing around the disk with the proboscis. This behaviour was also demonstrated by naive butterflies when they were sufficiently hungry.

We examined whether naive butterflies show a preference for disks of certain colours. Fig. 4 shows the distribution of colours visited for the first time by naive individuals $(N=35)$. The red and yellow disks were visited significantly more frequently than the green and blue disks.

\section{The learning process}

The preference for red and yellow of naive butterflies increased after training (Fig. 5). The first training session was performed on post-emergence day 2, and the first test was performed on post-emergence day 3 immediately before the second training session. Therefore, the results of red training
(Fig. 5A) indicate that the butterflies trained only once (on day 2) were already significantly attracted by the red disk presented with three other colours (blue, green and yellow). A similar phenomenon was observed for yellow (Fig. 5B).

The preference could be changed by training to other colours. When naive butterflies, which prefer red or yellow, were fed on a green disk once a day for 3 days, they started to visit green more frequently than other colours on postemergence day 5 (Fig. 5C). In the case of blue, the butterflies became significantly selective on post-emergence day 6 (Fig. 5D).

The preference for a trained colour could also be changed readily to other colours by another series of training sessions. For example, yellow-trained butterflies changed their preference to red after only a single experience of feeding on the red disk (data not shown).

\section{Learning results}

The effects of the 9 day training program (from postemergence days 2-10) were evaluated by presenting the 13colour pattern (Fig. 2C). Fig. 6 shows the cumulative results of tests with 57 individuals and shows clearly that these butterflies were attracted to the colour to which they had been trained. However, some confusion was also apparent. For example, the yellow-trained butterflies visited orange $(42 \%)$ as well as yellow (52\%). The blue-trained butterflies also visited light blue $(20 \%)$. However, the butterflies trained to grey were not specifically attracted by grey (bottom bar).

\section{Selection of the trained colour from shades of grey}

For all the individuals used for the experiment shown in

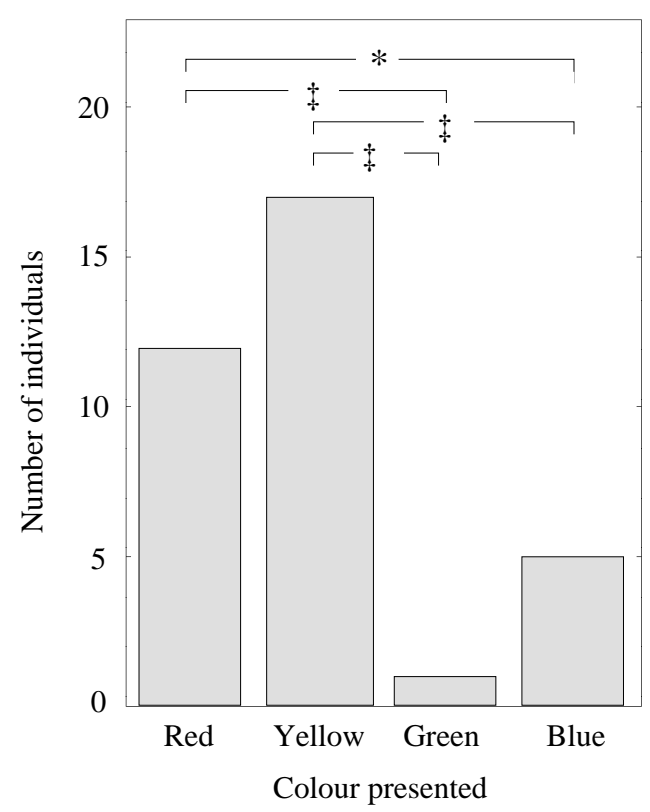

Fig. 4. Colours of disks visited by naive summer-form females for the first time. $\ddagger P<0.001 ; * P<0.05$ (Mann-Whitney $U$-test). 

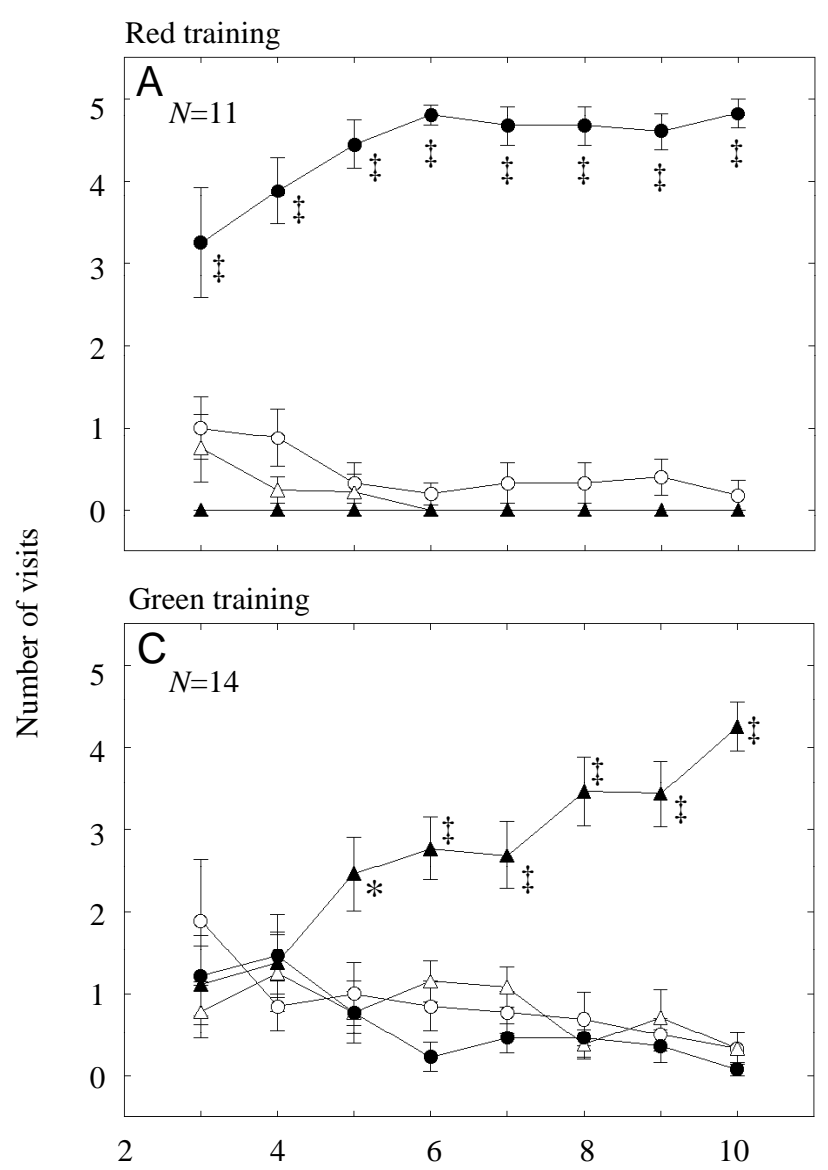

Yellow training

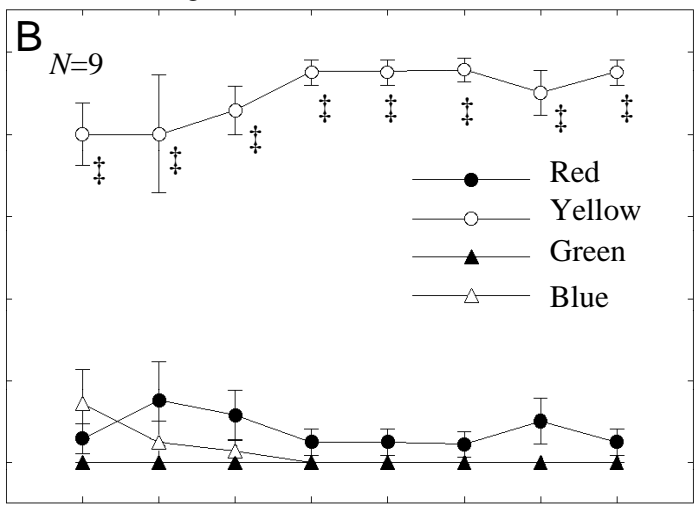

Blue training

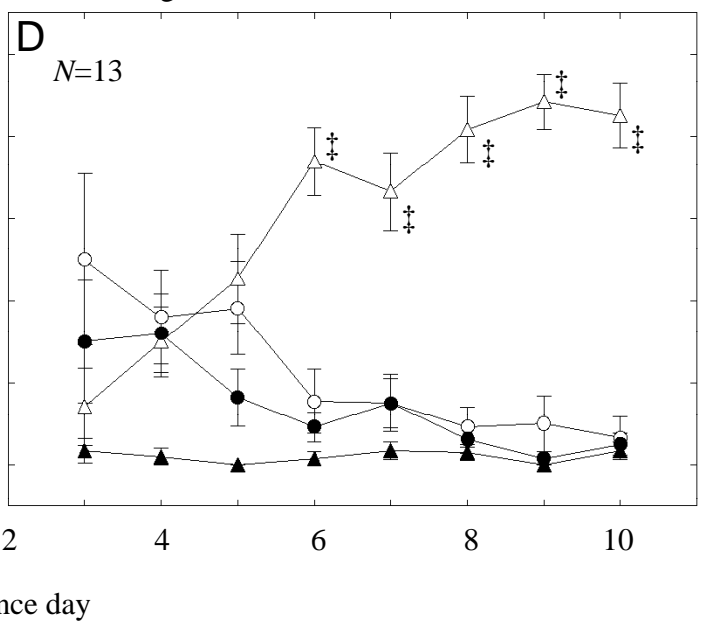

Fig. 5. Effect of training (lasting 9 days) on a disk of a particular colour. $*, \ddagger$ indicate that the training colour was selected significantly more often than any other colour. $\ddagger P<0.001 ; * P<0.05$ (Mann-Whitney $U$-test). Values are means \pm S.E.M.

Fig. 6, we subsequently presented the trained colour together with seven different shades of grey (Figs 2D, 3C). In all cases, the disk of the trained colour was correctly visited without exception: no greys were visited $(P<0.001$, data not shown).

\section{Response to stimuli with reduced brightness}

We presented the four-colour pattern with a neutral density filter (ND0-ND5) placed over the disks. After the butterfly had first visited the trained colour, the brightness of the disk of the trained colour was reduced by covering the disk with a neutral density filter: the disks of other colours were not covered. Table 1 summarizes the results. When presented with no reduction in brightness, all the individuals tested visited the learned colours correctly (ND0). In the red-trained butterflies, eight out of nine individuals visited the trained disk after the brightness had been reduced to $63 \%$; in green-trained butterflies, two out of three individuals visited the trained disk after the brightness had been reduced to $63 \%$. All the yellowtrained butterflies visited yellow after the disk had been covered with ND3 $(T=50 \%)$. One yellow-trained individual visited the yellow disk even after the disk had been covered with ND4 ( $T=40 \%)$, which made the yellow disk almost brown to human observers. The blue-trained butterflies, in contrast, did not visit a blue disk whose brightness had been reduced to $80 \%$ of its original value.

\section{Discussion}

The retina of Papilio xuthus contains at least five types of spectral receptor with sensitivity maxima in the ultraviolet $\left(\lambda_{\max }=360 \mathrm{~nm}\right)$, violet $(400 \mathrm{~nm})$, blue $(460 \mathrm{~nm})$, green $(520 \mathrm{~nm})$ or red $(600 \mathrm{~nm})$ region of the spectrum (Arikawa et al., 1987). Since the experimental arena was illuminated by light in the range $400-700 \mathrm{~nm}$ (Fig. 3D), the colour vision ability detected in these butterflies must depend mostly on blue, green and red receptors.

\section{Innate preference of summer-form females for red or yellow}

Most summer-form females of Papilio xuthus preferred disks of yellow or red as their first target (Fig. 4). Since these butterflies had never received any food until the experiments, this colour preference must be innate. However, we must note here that we presented coloured disks without attenuating the 
Fig. 6. The final results of the 9 day training, measured on day 11 using the 13-colour pattern. For the reflection spectrum of each colour, see Fig. 3. Abbreviations as in Fig. 3. The training colour and the number of individuals trained are shown to the left of the figure.

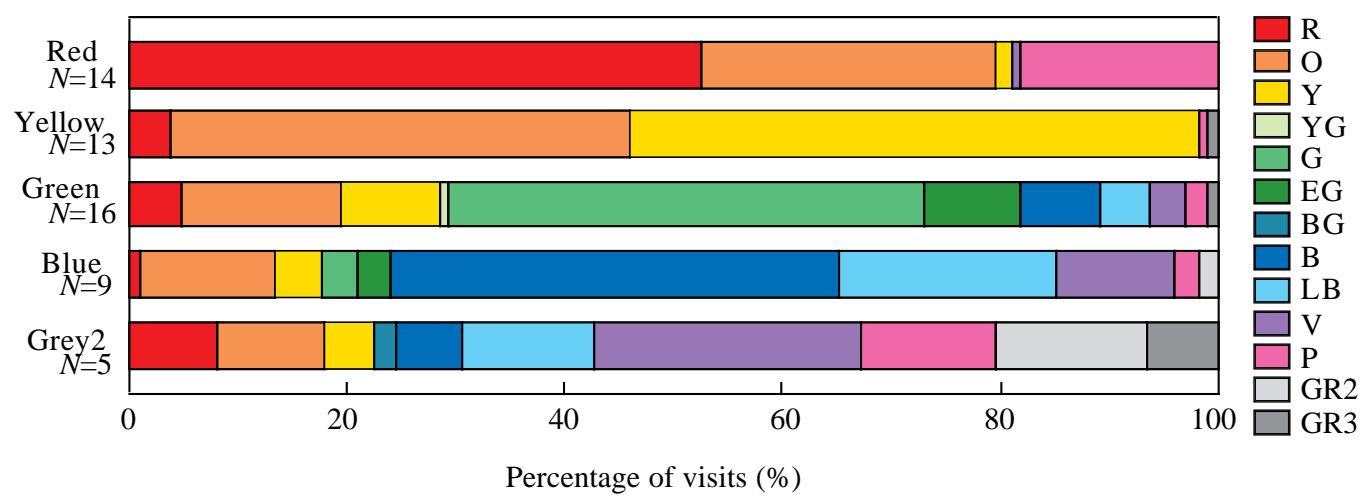

brightness (Fig. 3). Therefore, the butterflies may simply have chosen brighter disks.

The brightness of the coloured papers perceived by Papilio xuthus may, of course, be different from the brightness that we perceive. Here, the Papilio-subjective brightness $\left(B_{\mathrm{i}}\right)$ of the coloured paper $i$ under the present experimental condition was predicted by:

$$
B_{\mathrm{i}}=\int_{325}^{700} I(\lambda) R_{\mathrm{i}}(\lambda) S(\lambda) \mathrm{d} \lambda
$$

where $I(\lambda)$ is the irradiance spectrum of illumination (Fig. 3D), $R_{\mathrm{i}}(\lambda)$ is the reflectance spectrum of coloured paper $i$ (Fig. 3A-C), $S(\lambda)$ is the spectral sensitivity of Papilio xuthus determined by electroretinogram (ERG) recording (see also Arikawa et al., 1987) and $\lambda$ is wavelength. We must note here that the value of $S(\lambda)$ determined from an ERG is simply used as a close approximation of the spectral input to the colour vision system. There is a limitation to estimating the subjective brightness using this approach because the retinal sensitivity does not necessarily provide linear spectral input to the colour vision system that functions during foraging behaviour. At any rate, the calculated relative $B_{\mathrm{i}}$ values of the red, yellow, green and blue disks appeared to be 36.36 , $100.00,46.97$ and 49.37, respectively. Fig. 7 shows the function $I(\lambda) R_{\mathrm{i}}(\lambda) S(\lambda)$ for these four coloured papers.

If the result shown in Fig. 4 simply reflects the relative subjective brightness of the disks, the strong preference for red,

which is the darkest colour, cannot be explained. Previous results from other butterflies also indicate that the innately preferred colours were visited irrespective of their brightness (Scherer and Kolb, 1987a,b). Moreover, we have also noticed that summer-form males prefer blue, which is not the brightest colour, as their first target (M. Kinoshita and K. Arikawa, unpublished observation).

\section{Colour vision}

It now appears that Papilio xuthus can learn colours associated with food. The curves shown in Fig. 5 demonstrate the time courses of this associative learning. Red and yellow were most easily learned. This is probably due to the innate preference of the butterflies for these colours. Other colours took longer to be learned, probably because the butterflies need to change their innate preference to a new target. The mechanism underlying the quick change of colour preference must be important for efficient food searching in the field, where many different kinds of flowers exist simultaneously.

The procedure by which animals were tested for their ability to choose the trained colour from shades of grey (Fig. 2D) follows the conventional experimental design used many times in the past to demonstrate the colour vision ability of a particular animal (Frisch and Kuppelwieser, 1913; Fukushi, 1990; Marshall et al., 1996). The relative $B_{\mathrm{i}}$ value of the grey papers (yellow was taken as 100.00) used in the present experiments (Fig. 3C) were 194.14 (GR1), 147.00 (GR2), 108.67 (GR3), 71.08 (GR4), 48.96 (GR5), 31.22 (GR6) and

Table 1. Selection by butterflies of the correct colour of reduced brightness

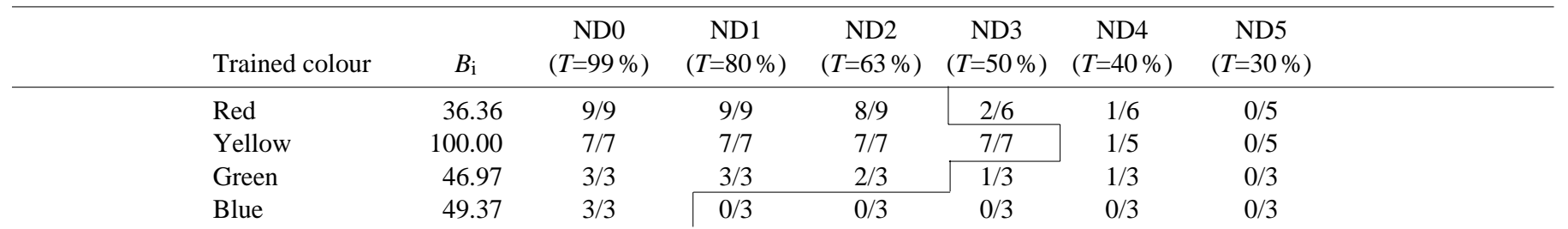

Brightness was reduced by covering the coloured disk with a neutral density filter.

Results are presented as the number of individuals that visited the correct colour/the number of individuals tested.

The line in the table indicates the level of brightness at which more than two-thirds of the individuals tested visited the correct colour. In all cases, the individuals that did not visit the correct colour never visited any colour.

ND, neutral density filter; $T$, transmittance; $B_{\mathrm{i}}$, the Papilio-subjective brightness of a coloured paper. 


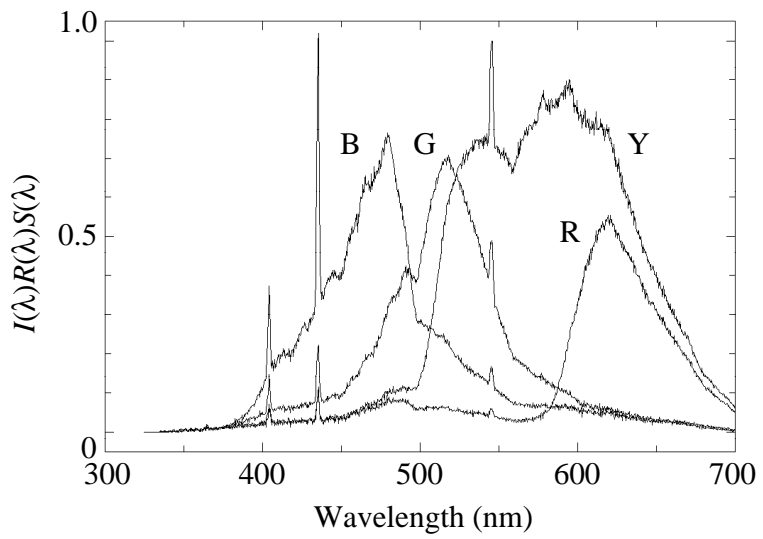

Fig. 7. The product of the irradiance spectrum, $I(\lambda)$, the reflectance spectrum of the coloured papers, $R_{\mathrm{i}}(\lambda)$, and the spectral sensitivity function, $S(\lambda)$, of Papilio xuthus determined by electroretinogram recording. See text for details. B, blue; G, green; Y, yellow; R, red.

20.24 (GR7). Some of them were, of course, brighter than the coloured papers used for the training. The butterflies showed a strong preference for the trained colour and never landed on any grey disks, even on those that were brighter than the trained colours. Moreover, butterflies trained to red, yellow and green visited the trained colour even after the brightness had been greatly reduced by covering the disks with neutral density filters (Table 1).

Unexpectedly, the blue-trained butterflies could not distinguish the blue disk when the brightness was reduced to $80 \%$ (Table 1). This phenomenon cannot be explained simply by the subjective brightness of the blue disk: there could be some mechanism specifically related to the perception of blue. This mechanism may be related to the spatial distribution of blue receptors in the retina. Our recent investigation on the retinal organization of Papilio xuthus has revealed that their ommatidia are spectrally heterogeneous. Briefly, among nine photoreceptor cells in an ommatidium (R1-R9), R1 and R2 are of the ultraviolet, violet or blue type, whereas R3 and R4 are green receptors (Bandai et al., 1992; Kitamoto et al., 1998): the frequencies of the ultraviolet, violet and blue receptors in the middle region of the compound eye are similar (K. Arikawa, unpublished observation). R5-R8 are either green (25\% of the ommatidia) or red (75\% of the ommatidia) receptors. R9 cells are also either of the green or red type, and the ratio of these two types is approximately 1:1 (Arikawa and Uchiyama, 1996). We have therefore tentatively identified four types of ommatidia with different combinations of spectral receptors; these results have been summarized elsewhere (Arikawa et al., 1999). It is particularly important to mention here that the different types of ommatidia are distributed randomly over the retina (Arikawa and Stavenga, 1997). This randomness makes the distribution of blue receptors more sparse compared with that of the green and red receptors. Such a retinal organization should result in low spatial resolution in the blue wavelength region, which makes the border of the blue disk ambiguous especially when the brightness of the disk is reduced. In fact, the butterflies often land near the edge rather than in the centre of a disk, implying that the recognition of the border is important for butterflies to determine whether to land there.

The results of the 9 day training clearly indicate that the butterflies learned colours, but had difficulty when they were trained on grey (Fig. 6). Nevertheless, one out of five greytrained butterflies visited grey disks more frequently $(P<0.05)$ than did butterflies trained to other colours. Our preliminary results have shown that grey can also be learned, but very slowly (M. Kinoshita and K. Arikawa, unpublished results). The nine training runs may not be sufficient for the butterflies to learn grey as the food source: they may eventually become strongly selective. However, there is still a possibility that the butterflies could have perceived the grey disks as 'slightly coloured' disks. Since the disks were illuminated by a strongly biased spectrum of light (Fig. 3B), they were not reflecting the whole spectrum equally. Therefore, even though the papers have neutral reflectance, they reflected a colour, which the butterflies might have interpreted as a particular hue.

\section{Perspectives}

Taken together, we conclude that foraging Papilio xuthus can discriminate colour disks on the basis of their chromatic content regardless of their brightness: they have true colour vision. Convincing demonstrations of true colour vision in invertebrates by behavioural experiments have been achieved in the honeybee Apis mellifera (Menzel and Backhaus, 1989), the blowfly Lucilia cuprina (Fukushi, 1989, 1990; Troje, 1993) and the mantis shrimp Odontodactylus scyllarus (Marshall et al., 1996). In spite of many published opinions that butterflies also share this ability, this is the first conclusive demonstration of butterfly colour vision. More details, such as the wavelength discrimination, colour constancy and categorical perception of colours by butterflies, remain to be determined.

The colour vision of Papilio xuthus under illumination containing ultraviolet light as well is, of course, another interesting problem. Under such illumination, all five types of spectral receptor, including the ultraviolet and violet receptors, must function together. Judging from the fact that the human trichromatic system is based on three types of spectral receptor, the colour vision system of Papilio xuthus could be pentachromatic, which may involve four colour opponencies and provide the animal with a five-dimensional colour space.

We thank Drs G. D. Bernard, T. H. Goldsmith and T. W. Cronin for critical reading of the manuscript. The work was supported by Research Grants from the Ministry of Education, Science, and Culture of Japan to K.A.

\section{References}

Arikawa, K., Inokuma, K. and Eguchi, E. (1987). Pentachromatic visual system in a butterfly. Naturwissenschaften 74, 297-298. 
Arikawa, K., Scholten, D. G. W., Kinoshita, M. and Stavenga, D. G. (1999). Tuning of photoreceptor spectral sensitivities by red and yellow pigments in the butterfly Papilio xuthus. Zool. Sci. (in press).

Arikawa, K. and Stavenga, D. G. (1997). Random array of colour filters in the eyes of butterflies. J. Exp. Biol. 200, 2501-2506.

Arikawa, K. and Uchiyama, H. (1996). Red receptors dominate the proximal tier of the retina in the butterfly Papilio xuthus. J. Comp. Physiol. A 178, 55-61.

Bandai, K., Arikawa, K. and Eguchi, E. (1992). Localization of spectral receptors in the ommatidium of butterfly compound eye determined by polarization sensitivity. J. Comp. Physiol. A 171, 289-297.

Frisch, K. V. and Kuppelwieser, E. M. (1913). Über den Einfluß der Lichtfarbe auf die phototakische Reaktion niederer Krebse. Biol. Zentralbl. 33, 517-522.

Fukushi, T. (1989). Learning and discrimination of coloured papers in the walking blowfly, Lucilia cuprina. J. Comp. Physiol. A 166, 57-64.

Fukushi, T. (1990). Colour discrimination from various shades of grey in the trained blowfly, Lucilia cuprina. J. Insect Physiol. 36, 69-75.

Goldsmith, T. H. (1990). Optimization, constraint and history in the evolution of eyes. Q. Rev. Biol. 65, 281-322.

Goulson, D. and Cory, J. S. (1993). Flower constancy and learning in foraging preferences of the green-veined white butterfly Pieris napi. Ecol. Ent. 18, 315-320.

Ilse, D. and Vaidya, V. G. (1955). Spontaneous feeding response to colours in Papilio demoleus L. Proc. Ind. Acad. Sci. 43, 23-31.

Kandori, I. and Ohsaki, N. (1998). Effect of experience on foraging behavior towards artificial nectar guide in the cabbage butterfly, Pieris rapae crucivora (Lepidoptera: Pieridae). Appl. Ent. Zool. 33, 35-42

Kitamoto, J., Sakamoto, K., Ozaki, K., Mishina, Y. and Arikawa, K. (1998). Two visual pigments in single photoreceptor cells: identification and histological localization of three mRNAs encoding visual pigment opsins in the retina of the butterfly Papilio xuthus. J. Exp. Biol. 201, 1255-1261.

Marshall, N. J., Jones, J. P. and Cronin, T. W. (1996). Behavioural evidence for colour vision in stomatopod crustaceans. J. Comp. Physiol. A 179, 473-481.

Menzel, R. (1985). Colour pathways and colour vision in the honeybee. In Central and Peripheral Mechanisms of Colour Vision (ed. D. Ottoson), pp. 211-233. Macmillan.

Menzel, R. and Backhaus, W. (1989). Color vision in honey bees: Phenomena and physiological mechanisms. In Facets of Vision (ed. D. G. Stavenga and R. C. Hardie), pp. 281-297. Berlin, Heidelberg, New York, London, Paris, Tokyo: Springer-Verlag.

Scherer, C. and Kolb, G. (1987a). Behavioral experiments on the visual processing of color stimuli in Pieris brassicae $\mathrm{L}$. (Lepidoptera). J. Comp. Physiol. A 160, 645-656.

Scherer, C. and Kolb, G. (1987b). The influence of color stimuli on visually controlled behavior in Aglais urticae L. and Pararge aegeria L. (Lepidoptera). J. Comp. Physiol. A 161, 891-898.

Silberglied, R. E. (1984). Visual communication and sexual selection among butterflies. In The Biology of Butterflies (ed. R. J. VaneWright and P. R. Ackery), pp. 207-223. London: Academic Press.

Troje, N. (1993). Spectral categories in the learning behaviour of blowflies. Z. Naturforsch. C 48, 96-104.

Weiss, M. R. (1997). Innate colour preferences and flexible colour learning in the pipivine swallowtail. Anim. Behav. 53, 1043-1052. 